\title{
Effects of the Hand Care Therapy that Used Natural Herb Oil on Autonomic Nervous System against All People Concerned
}

\author{
Akiko Ikeda ${ }^{1,2 *}$, Hiroya Miyabara ${ }^{1}$, Kentaro Higashi ${ }^{3}$, Tmohiro Inagaki ${ }^{3}$, Chieko Nishikawa ${ }^{3}$, \\ Kazuho Nagao ${ }^{3}$, Seigo Koura ${ }^{1}$
}

${ }^{1}$ Faculty of Rehabilitation, Nishikyusyu University, Kanzaki, Saga, Japan

${ }^{2}$ Sophia Phyto-Therapy College, Tokyo, Japan

${ }^{3}$ Social Welfare Corporation Kanjikai, Miyakonojyo, Japan

Email: *melissa@sophia-college.jp

How to cite this paper: Ikeda, A., Miyabara, H., Higashi, K., Inagaki, T., Nishikawa, C., Nagao, K. and Koura, S. (2021) Effects of the Hand Care Therapy that Used Natural Herb Oil on Autonomic Nervous System against All People Concerned. Open Journal of Therapy and Rehabilitation, 9, 132-142.

https://doi.org/10.4236/ojtr.2021.94011

Received: October 15, 2021

Accepted: November 19, 2021

Published: November 22, 2021

Copyright $\odot 2021$ by author(s) and Scientific Research Publishing Inc. This work is licensed under the Creative Commons Attribution International License (CC BY 4.0).

http://creativecommons.org/licenses/by/4.0/

(c) (i) Open Access

\begin{abstract}
Multi-sensory stimulation is beneficial to a wide variety of conditions typical of geriatric patients. Some therapies for elderly people are based on the philosophy that the activities to be carried out will also be stimulating to the senses. On the other hand, the dynamics of the senses plays an important role beyond mere reason and sensibility in people's lives. The hand care therapy that used natural herb oil is the alternative medicine that utilized a plant or its essential oil, which is used in various application scenes. In our past study, the hand care therapy that used natural herb oil demonstrated the effectiveness for elderly people. In this study, we examined influences on psychological condition of the side to treatment on. On the evaluation with question paper, baseline of POMS factor and TMD average were similar to pre-HCT. In post-HCT, T-A, A-H, F and C which were negative factors decreased than pre significantly. The forward factor $\mathrm{V}$ did not have significant difference, but the mean increased. Furthermore, the TMD (total mood distance) score generally decreased and changed in the balance of good feelings. On the objective evaluation, temporal change differences in the PNS (Parasympathetic Nervous System) during the relaxed state and following the induced stress state were monitored using ECG (electrocardiograph). The SNS (Sympathetic Nervous System) of students in HCT has decreased, and the PNS was confirmed to increase. For the tendency in SNS, the changes during the HCT were small. There were no significant changes in $\mathrm{rSO}_{2}$ (regional oxygen saturation) by HCT. BVI (blood volume information) showed significantly big values at left hand treatment and after HCT than BL, indicating that peripheral circulation of the blood flow quantity of the student increased. Generally, it was shown that the subjective emotional evaluation of the hand care treatment side, the
\end{abstract}


objective autonomic nervous system change, and the coronal blood flow were all good. In Japan, the global pandemic of COVID-19 disrupts human interaction, and there are concerns about physical, cognitive, and mental deterioration. The use of hand care therapy has been shown to be an effective technique for building quality communication for both recipients and performers.

\section{Keywords}

Hand Care Therapy, Para-Sympathetic Nervous System (PNS), Sympathetic Nervous System (SNS), Emotional Health, COVID-19

\section{Introduction}

Psychogeriatric medical care often takes time. Particularly, the care for person with dementia takes more time. Therefore, not only the care of the psychological conditions of the elderly person, but also the care of the medical person side is important. Multi-sensory stimulation is beneficial to a wide variety of conditions typical of geriatric patients. Changes appeared in muscle tension, skin conductance and pulse that correlates with reduced blood pressure [1] [2]. Various studies of horticultural therapy programs have demonstrated the positive effects on schizophrenic behaviour and those suffering from depression [3]. In other words, engaging in horticultural activities may help improve the stability of the mind and generally facilitate a much broader and more positive attitude.

It has been reported that students participating in horticulture therapy programs developed a greater interest in the welfare of others and that the student's own feelings became more positive [4] [5] [6]. Horticultural therapy is based on the philosophy that the activities to be carried out will also be stimulating to the senses. It is one big characteristic of the horticultural therapy, and it is an advantage [7]. On the other hand, the dynamics of the senses plays an important role beyond mere reason and sensibility in people's lives. The hand care therapy (HCT) included in the horticultural therapy which is the alternative medicine that utilized a plant, or its essential oil is utilized in various application scenes.

In recent studies, the hand care therapy that used natural herb oil demonstrated the effectiveness for the elderly people and showed that it had many good influences on the psychological condition of the side that performs HCT. We want to clarify a mental or psychological effect of HCT [8] [9]. It was intended to exhibit the subjective and objective reaction of HCT.

According to a report from the Philippines, COVID-19 became more severe in cases with a vitamin D concentration of less than $30 \mathrm{ng} / \mathrm{mL}$, whereas it was mostly mild in cases with a vitamin $\mathrm{D}$ concentration of $30 \mathrm{ng} / \mathrm{mL}$ or more. It was presumed that the risk of dementia progression increases as the new lifestyle of isolation continues [10]. In other words, behavioural restrictions and lack of communication between humans caused by the spread of COVID-19 should be considered to have an adverse effect on various diseases. On the other hand, 
utilizing HCT that utilizes the power of nature and plants for the elderly, it was expected to lead to prevention cognitive impairment and behaviour such as depressive views and depressive tendencies by COVID-19 [11] [12]. In addition, behavioural restrictions are due to the spread of COVID-19, while many citizens had a tendency toward depression and ADL reduction due to behavioural restrictions [13] [14]. The adverse effects of these COVID-19 behavioural restrictions have also been reported to worsen the mental state of medical personnel [15]. In this study, we examined how much HCT, which facilitates the construction of high-quality communication, can contribute to the mental stability of the treating side, and considered the importance of HCT dissemination in the COVID-19 prevalence state.

\section{Material and Methods}

\subsection{Surgical Students and Subjects}

Of the 164 students belonging to the Department of Occupational Therapy at University B, 17 were qualified as phytotherapy college-certified hand care therapists and agreed to this study. The elderly in this study lived in A city, with a population of about $160,000,31.8 \%$ of those aged 65 and over and $16.1 \%$ of those aged 75 and over, which was the average region in Japan. Seventeen healthy student volunteers ( 8 male and 9 female; mean age $21.4 \pm 0.7$ years) were enrolled. The 17 students practiced HCT treatment for the elderly and Before and after the activity, mood evaluation was performed using VAS (visual analog scale) and POMS (Profile of Mood States), and changes over time in ANS (autonomic nervous system), $\mathrm{rSO}_{2}$ (regional oxygen saturation) and BVI (blood volume information) were measured during HCT practice. The measurement results were tabulated for each work procedure and shown in a graph.

Subjective reaction of surgical operation student of HCT for the elderly entrance person in care health centre was investigated at pre and post HCT. Objective reaction of surgical operation student of HCT for the elderly entrance person was investigated during HCT. The times required for every event were Preparation; 2 - 3 min., Base Line Resting; 3 min., Interval 1; 1 min., Right hand HCT; 5 - 7 min., Interval2; 1 - 2 min., Left hand HCT: 5 - 7 min., Rest after HCT; 3 - 5 min.

\subsection{Material and Time of Subjective Evaluation, Questionnaire Paper Evaluation and Objective Evaluation}

Material and time of subjective evaluation, questionnaire paper evaluation and objective evaluation were shown at Table 1.

The subjective evaluation was VAS, the question paper evaluation enforced POMS (Profile of Mood States) and subjective evaluation include ANS and INVOS were included in an objective evaluation.

POMS investigation was used to measure changes in students' moods and emotions [16] [17] [18] [19]. The POMS consists of 65 single-word items rated 
Table 1. Evaluation methods or aim and material.

\begin{tabular}{|c|c|c|}
\hline & Methods or Aim & Time, Material \\
\hline Subjective evaluation & VAS (Visual Analog Scale) & $\begin{array}{l}\text { Pre \& Post of HCT } \\
\text { Relax } \rightarrow \text { strain }\end{array}$ \\
\hline $\begin{array}{l}\text { Questionnaire paper } \\
\text { evaluation }\end{array}$ & $\begin{array}{l}\text { POMS (Profile of Mood } \\
\text { States) }\end{array}$ & Pre \& Post of HCT \\
\hline Objective evaluation & $\begin{array}{l}\text { Autonomic nervous } \\
\text { system measurement }\end{array}$ & $\begin{array}{l}\text { A surgical operation all the time } \\
\text { A spectral } \\
\text { ECG (Electrocardiogram) was performed using software, MemCalc/Tarawa } \\
\text { system (GMS, Japan). The sympathetic nervous system (SNS: LF/HF) has been } \\
\text { retracted, the parasympathetic nervous system (PNS: HF) was confirmed to be } \\
\text { enhanced. }\end{array}$ \\
\hline
\end{tabular}

from 0 (not at a11) to 4 (extremely). We compared the results of the POMS tests measuring student's tension-anxiety (T-A), depression-dejection (D), angerhostility $(\mathrm{A}-\mathrm{H})$, vigour-activity $(\mathrm{V})$, fatigue-inertia $(\mathrm{F})$ and confusion-bewilderment (C) before (pre-HT, CT) and after (post HT, CT) HCT. The score of POMS was shown by $\mathrm{T}$ score $(\mathrm{T}$ score $=50+10 \times$ (standard score-average)/standard deviation), and total mood distance (TMD method $=\mathrm{T}-\mathrm{A}+\mathrm{D}+$ $\mathrm{A}-\mathrm{H}+\mathrm{F}+\mathrm{C}-\mathrm{V}$ ) that showed overall moods and emotions were used. It is shown that feelings are steady when TMD points are low, and if it is at 100 points, it is excellent. POMS reliability and validity is well supported by literature.

\subsection{ANS Change Measurement (A Spectral ECG Analysis)}

A spectral ECG analysis (heart rate variance: HRV analysis) was performed using software, MemCalc/Tarawa system (GMS, Japan), which is a non-invasive, real-time analysis system [20] [21]. The low-frequency (LF: $0.04-0.15 \mathrm{~Hz}$ ) component reflects sympathetic and parasympathetic modulation, whereas the high-frequency (HF: $0.15-0.4 \mathrm{~Hz}$ ) component mainly reflects parasympathetic modulation. Electrocardiogram (ECG) was measured using a continuous wave frequency spectrum analysis, the sympathetic nervous system (SNS: LF/HF) has been retracted, the parasympathetic nervous system (PNS: HF) was confirmed to be enhanced (Figure 1).

\subsection{Somatic 0xi-Meter Analysis}

INVOS $^{\text {TM }} 5100 \mathrm{C}$ cerebral/somatic oxi-meter (manufacturer: Medtronic Usa) provides real-time monitoring of site-specific blood oxygen saturation in the brain and other body tissues to help surgical and intensive care teams detect and correct ischemic problems that can lead to complications and poor outcomes (Figure 2) [22] [23].

The original purpose of this medical device: Monitors real-time changes in regional oxygen saturation of blood in the brain or other body tissues beneath the sensor for effective oxygen monitoring in adults, children, infants and neonates, Allows clinicians to measure site-specific oxygen levels rather than requiring 

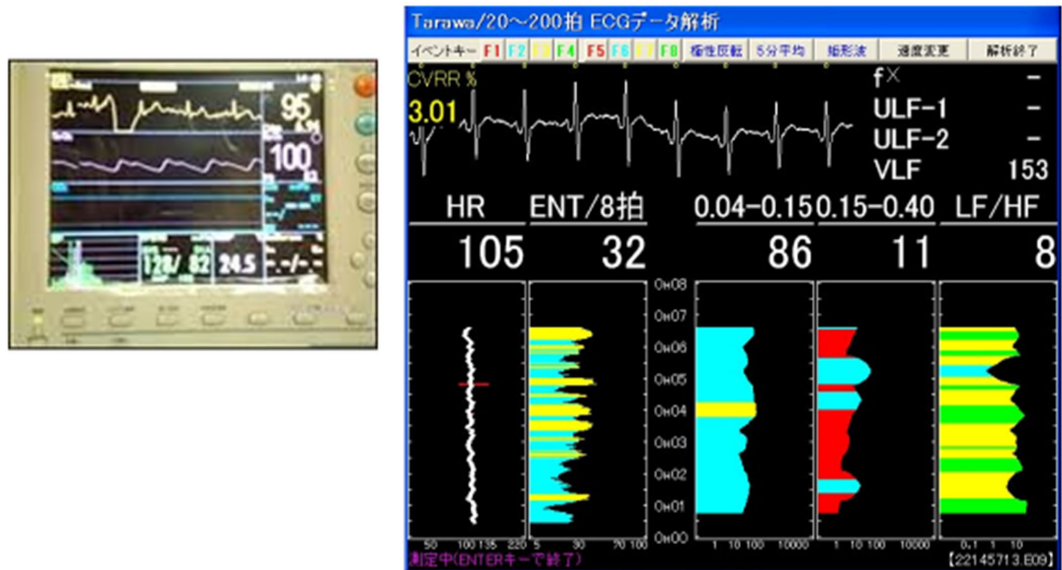

ECG monitor + Mem calc analysis soft (GMS co. Ltd. Mem Calc/Tarawa)

Figure 1. A temporal change of the Parasympathetic Nervous System (PNS) of a relaxed state and the Sympathetic Nervous System (SNS) of a strain state was measured using ECG and analysis software (GMS co. Ltd. Mem Calc/Tarawa). ${ }^{\star} \mathrm{HF}$ value $=\mathrm{PNS}, \mathrm{LF} / \mathrm{HF}$ value $=$ SNS. LF: $0.04-0.15 \mathrm{~Hz}$ reflects parasympathetic function and some sympathetic function. HF: $0.15-0.4 \mathrm{~Hz}$ is related to respiratory and heart rate variability, PNS function almost and that is reflected in the indicators used in the SNS ratio LF/HF.

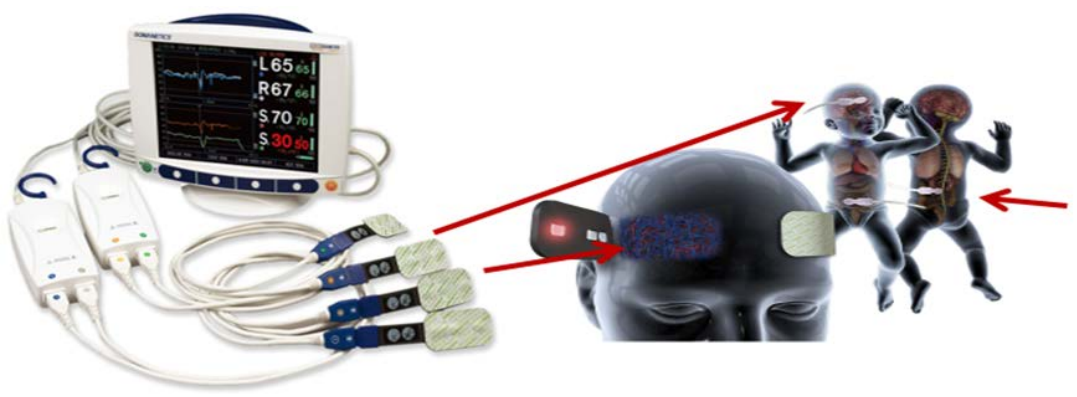

Figure 2. Evaluation with medical equipment studying now INVOS (IN Vivo Optical Spectroscopy).

them to infer the data from systemic, whole-body measures such as blood pressure and pulse oximetry, Available in two or four data channels, the INVOS system conveniently monitors multiple brain and body areas at once. In this study, two sensors are attached to the front face of the student in charge of HCT, and $\mathrm{rSO}_{2}$ and BVI of the total blood flow $3 \mathrm{~cm}$ below the sensors are measured. Then, the change in the practitioner's emotions was measured.

Mixed blood oxygen saturation during brain bloodstream was inspected with autonomic nerve. No aggression mixture blood oxygen saturation monitoring system $\mathrm{rSO}_{2}$; regional oxygen saturation

$$
\mathrm{rSO}_{2}=\frac{\mathrm{O}_{2} \mathrm{Hb} \text { of arterial and venous blood }}{\left(\mathrm{O}_{2} \mathrm{Hb} \text { of arterial and venous blood }\right)+(\mathrm{RHb})} .
$$

\subsection{Statistical Analysis}

Wilcoxon signed rank sum test was used for comparison between two groups for which a normal distribution cannot be assumed (Table 2). 
Table 2. Changes of students in POMS $t$ and TMD score from baseline and pre \& post-HCT activities, (mean \pm SD).

\begin{tabular}{cccccccc}
\hline \multirow{2}{*}{ Answer time } & \multicolumn{7}{c}{ Average t-score of POMS and TMD value (n = 17) } \\
\cline { 2 - 8 } & T-A & D & A-H & V & F & C & TMD \\
\hline Base Line & $45.3 \pm 8.6$ & $49.0 \pm 8.5$ & $45.1 \pm 6.2$ & $50.7 \pm 5.0$ & $45.4 \pm 5.5$ & $45.3 \pm 8.1$ & $179.1 \pm 17.3$ \\
\hline \multicolumn{7}{c}{ HCT } \\
Before & $46.9 \pm 5.5$ & $51.6 \pm 9.9$ & $46.9 \pm 8.9$ & $50.2 \pm 8.4$ & $45.8 \pm 6.9$ & $45.6 \pm 7.4$ & $186.6 \pm 27.9$ \\
After & $42.9 \pm 5.8$ & $48.5 \pm 7.7$ & $44.3 \pm 7.2$ & $50.9 \pm 15.6$ & $44.5 \pm 8.6$ & $43.3 \pm 8.1$ & $172.1 \pm 27.4$ \\
S.D. (p-Value) & $* *$ & $*$ & $* *$ & ns & ns & $*$ & $* *$ \\
\hline
\end{tabular}

${ }^{*},{ }^{* *}$ : Mean separation within Pre the activities start and Post HCT indicate 0.05 and 0.01 significant differences, respectively. ns: no significant. Base line: 7 days before activities.

The results of ANS were shown as mean $\pm \mathrm{SD}$ (min-max), Interquartile range, Median, statistical significance was checked. The One-way analysis of variance, multiple comparisons Tukey tests were performed in Evaluation of various questionnaires.

\subsection{Ethical Considerations}

We strictly observed the Helsinki Declaration of 2015 (revised in 2013), explained the purpose and outline of this study to them and obtained informed consent from them beforehand. All procedures were approved by the NishiKyushu University (Saga, Japan) Ethics Committee (H29-5, 2017).

\section{Results}

\subsection{Subjective Evaluation}

Figure 3 showed the results of VAS evaluation on subjective feelings of students. The feelings of students became strong in the tendency that could be relaxed clearly by operating for HCT.

\subsection{Evaluation with Question Paper}

Table 2 showed the POMS evaluation with questions about the mood state of students. Baseline of POMS factor and TMD average were similar to pre-HCT. In post-HCT, $\mathrm{T}-\mathrm{A}, \mathrm{A}-\mathrm{H}$ and $\mathrm{C}$ which were negative factors decreased than pre significantly. In addition, F, the negative feelings factor did not have significant difference, but the mean decreased. The forward factor $\mathrm{V}$ did not have significant difference, but the mean increased. Furthermore, the TMD score generally decreased and changed in the balance of good feelings.

\subsection{Objective Evaluation}

Temporal change differences in the Parasympathetic Nervous System (PNS) during the relaxed state and following the induced stress state were monitored using electrocardiograph (ECG). The SNS of students in HCT has decreased, and the parasympathetic nervous system (PNS) was confirmed to increase (Figure 4). 


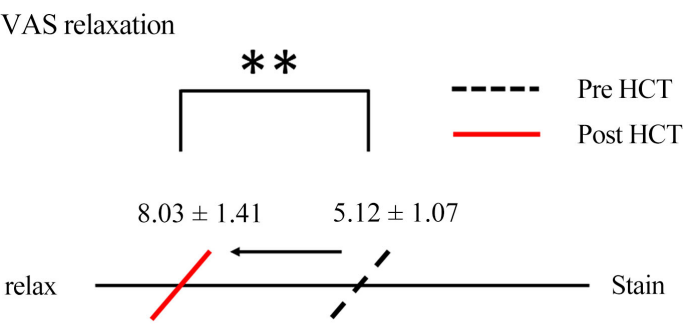

Figure 3. Comparison of VAS (relaxation) before and after HCT on surgical operation person of the student $(\mathrm{N}=17){ }^{* *}$ : Mean separation within Pre the activities start and Post the activities over months indicate 0.01 significant differences, respectively.

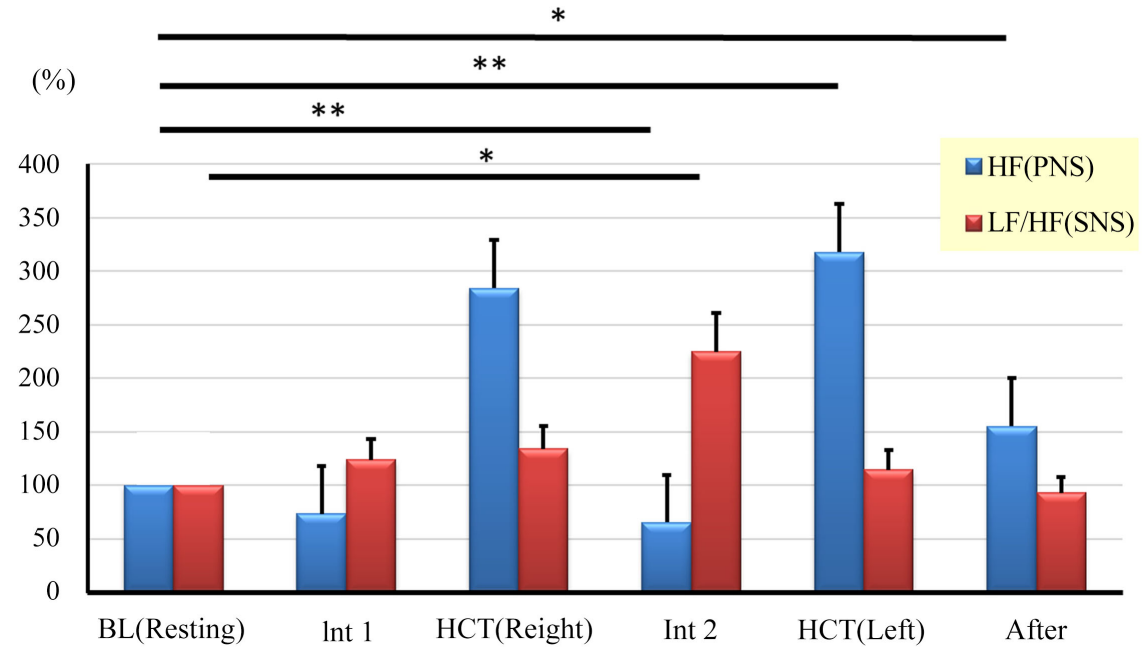

Figure 4. Time course of HF (PNS) and LF/HF (SNS) of students on HCT for elderly peoples. $\mathrm{N}=17, \mathrm{BL}=100 \%$. The data collection time for each was Preparation; 2 - $3 \mathrm{~min}$., Base Line Resting; 3 min., Interval 1; 1 min., Right hand HCT; 5 min., Interval 2; 1min., Left hand HCT: 5. It was min., Rest after HCT; $3-5 \mathrm{~min}$. And statistical comparison was made using their average values. ${ }^{*}{ }^{* *}$ : Mean separation within Pre the activities start and Post HCT indicate 0.05 and 0.01 significant differences, respectively. Base line: 7 days before activities.

For the tendency in SNS, the changes during the HCT were small. Nevertheless, only at the time of Int2, SNS significantly increased, in comparison with BL. As for this, it was thought that int2 had too short preparation time for the next surgical operation. The PNS significantly increased in comparison with BL at the time of HCT. In addition, an increased trend continued after HCT. It was indicating a bigger effective HCT for student's relaxation and the feeling of happiness.

There were no significant changes in $\mathrm{rSO}_{2}$ by HCT. BVI showed significantly big values at Left hand treatment and After HCT than BL, indicating that peripheral circulation of the blood flow quantity of the student increased (Figure 5).

From this, it was estimated that relaxation effects can be obtained by the action of $\mathrm{HF}$ (PNS), LF/HF (SNS), $\mathrm{rSO}_{2}$ and BVI in HCT. 


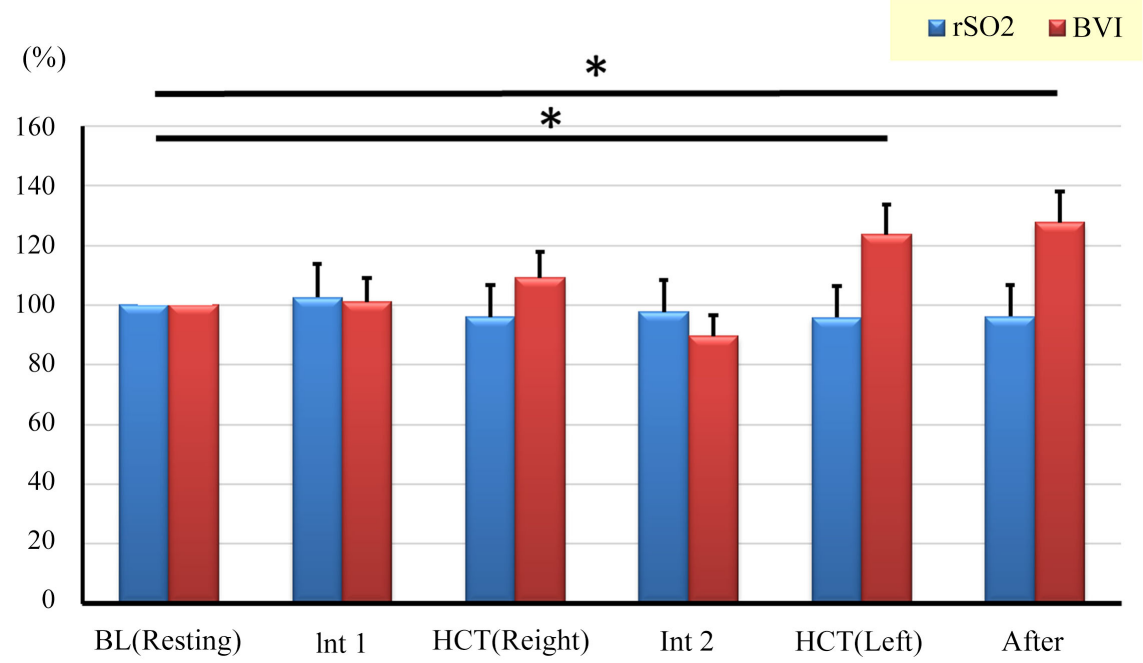

Figure 5. Time course of frontal plane $\mathrm{rSO}_{2}$ and BVI of students on HAM for elderly peoples. $\mathrm{N}=17, \mathrm{BL}=100 \%$. The data collection time for each was Preparation; 2 - $3 \mathrm{~min}$., Base Line Resting; 3 min., Interval 1; 1 min., Right hand HCT; 5 min., Interval 2; 1min., Left hand HCT: 5. It was min., Rest after HCT; 3 - 5 min. And statistical comparison was made using their average values. ${ }^{\star},{ }^{*}$ : Mean separation within Pre the activities start and Post HCT indicate 0.05 and 0.01 significant differences, respectively. Base line: 7 days before activities.

\section{Discussion}

In general, it became clear that the relaxation effect to a surgical operation person was seen in both subjective evaluation and objective evaluation. This showed that HCT was effective for caregivers such as dementia which long-term medical treatment is necessary.

As HCT technique are utilized at various hospitals, facilities for senior citizens, and facilities for the disabled because they involve a wide range of work activities and tools, and they also offer numerous types of sensory stimulation. In addition, as a result of POMS, the students who performed the treatment were often thanked by the elderly patients who received the treatment, so it was considered that they were able to reconfirm their role and existence value. HCT is a healing technique with the potential of enriching and brings happiness into participant's lives. When implementing HCT at a nursing home as a care technique for elderly persons, it is necessary to understand their usefulness. The benefits of HCT techniques can be observed not only in the area of general therapeutic application, but also in overall positive effects on emotional health of the participants, therapists and all related personnel.

In each country, the effects of the COVID-19 pandemic in people with dementia and those without dementia have been investigated, and the magnitude of the risk of people with dementia being infected with COVID-19 has been stated [24] [25] [26] [27] [28].

Super-aging in Japan, the global pandemic of COVID-19 disrupts human interaction, and there are concerns about physical, cognitive, and mental deterio- 
ration [29] [30] [31] [32]. The use of HCT has been shown to be an effective technique for building quality communication for both recipients and performers. Therefore, it was expected that the widespread use of HCT would promote interaction among all citizens involved in the COVID-19 epidemic and reduce frailty-induced physical and psychological disorders such as decreased brain function.

\section{Conclusion}

From previous studies, it was known that HCT amplifies the subject's sense of well-being. In addition, the conditioning effect of autonomic nervous system and emotional health were expected to the surgical operation person (therapist) of the hand care therapy too. Therefore, it was expected that the widespread use of HCT would promote interaction among all citizens involved in the COVID19 epidemic and reduce frailty-induced physical and psychological disorders such as decreased brain function.

\section{Disclaimer}

Since this study is the result of one region of Japan, verification in regions with different medical, health, welfare environments and cultures were insufficient. Therefore, it is necessary to continue the research in the future.

\section{Acknowledgements}

We would like to thank all staff members of Sophia Phyto-Therapy College and Social Welfare Corporation Kanjikai.

\section{Conflicts of Interest}

The authors declare no conflicts of interest regarding the publication of this paper.

\section{References}

[1] Wise, J.A. and Rosenberg, E.J. (1988) The Effects of Interior Treatments on Performance Stress in Three Types of Mental Tasks. Ctr. Integrated Facilities Res. Technical Rpt. No. 002-02-1988. Grand Valley State Univ., Allendale.

[2] Ulrich, R.S., Simons, R.F., Losito, B.D., Fiorito, E., Miles, M.A. and Zelson, M. (1991) Stress Recovery during Exposure to Natural and Urban Environments. Journal of Environmental Psychology, 11, 201-230. https://doi.org/10.1016/S0272-4944(05)80184-7

[3] Song, J. and Sim, W. (1999) An Experimental Study on the Effects of Horticultural Therapy-With Special Reference to Negative Symptoms of Schizophrenia. In: Burchett, M.D., Tarran, J. and Wood, R., Eds., Towards a New Millennium in PeoplePlant Relationships, University of Technology, Sydney, 292-300.

[4] Koura, S., Furukawa, C., Yamagishi, K. and Nomura, J. (2002) An Attitude Survey of the University Students Who Participated as Volunteers in Horticultural Therapy at Some Welfare Facilities for Aged People. Journal of Japanese Society of PeoplePlant Relationships, 1, 25-27. 
[5] Koura, S., Furukawa, C. and Nomura, J. (2002) Awareness Study of University Students Who Performed Horticultural Therapy in a Nursing Home. JSPPR Journal, 2, 12-16.

[6] Koura, S., Nagae, T. and Hara, T. (2006) A Study on Changes in Student Responses before and after Horticultural Activities and Horticultural Therapy Activities. A Minami-Kyushu University Study Report. Natural Science, No. 36(A), 21-30.

[7] Koura, S. and Yamagishi, K. (2005) Stimulation Senses Evaluating Student Responses to Horticultural Therapeutic Activities and Blindfolded Harvest of Blueberry. ISHS Acta Horticulturae 672: IV International Symposium on Horticultural Education, Extension and Training, Perth, 18-21 August 2004, 185-189. https://doi.org/10.17660/ActaHortic.2005.672.21

[8] Kunikata, H. (2012) The Effects Measurement of Hand Massage by the Autonomic Activity and Psychological Indicators. The Journal of Medical Investigation, 59, 206 212. https://doi.org/10.2152/jmi.59.206

[9] Kawahara, Y. (2009) Nurses Experiences of Touch Care: An Analysis from the Perspective of Corporeality in the Art of Nursing. Japanese Journal of Nursing Art and Science, 8, 46-55.

[10] Chai, B.Y., Gao, F.L., Wu, R.P., Dong, T., Gu, C., Lin, Q.R. and Zhang, Y. (2019) Vitamin D Deficiency as a Risk Factor for Dementia and Alzheimer's Disease: An Updated Meta-Analysis. BMC Neurology, 19, Article No. 284. https://doi.org/10.1186/s12883-019-1500-6

[11] Koura, S., Ikeda, A., Fujioka, Y., Mizogami, Y., Higashi, K. and Oshikawa, T. (2020) Effects of Hand Care Therapy on Reducing the Conversion Rate from MCI to Dementia and Role of COVID-19 as Non-Pharmacotherapy. Open Journal of Therapy and Rehabilitation, 8, 42-52. https://doi.org/10.4236/ojtr.2020.83004

[12] Koura, S., Ikeda, A., Semba, R., Ito, M., Nagao, K., Higashi, K., Kumura, Y., Yokota, H. and Matsutani, S. (2021) Effectiveness of Hand Care Therapy and Garden Walks That Are Conscious of the Stimulation of the Five Senses for Recovery of Cognitive and Mental and Physical Dysfunction Caused by COVID-19. Open Journal of Therapy and Rehabilitation, 9, 10-27. https://doi.org/10.4236/ojtr.2021.91002

[13] Saito, N. (2021) Depression in COVID-19 Shock: From an Immunological Point of View. Japanese Society of Psychosomatic Internal Medicine, 25, 74-80.

[14] Chmielewska, B., Barratt, I., Townsend, R., Kalafat, E., Meulen, J., Gurol-Urganci, I., O’Brien, P., Morris, E., Draycott, T., Thangaratinam, S., Le Doare, K., Ladhani, S., Dadelszen, P., Magee, L. and Khalil, A. (2021) Effects of the COVID-19 Pandemic on Maternal and Perinatal. The Lancet Global Health, 9, e759-e772. https://doi.org/10.1016/S2214-109X(21)00079-6

[15] FuJino, Y., Ishimaru, T., Eguchi, H., Tsuji, M., Tateishi, S., Ogami, A., Mori, K. and Matuda, S. (2021) Protocol for a Nationwide Internet-Based Health Survey of Workers during the COVID-19 Pandemic in 2020. Journal of UOEH, 43, 217-225. https://doi.org/10.7888/juoeh.43.217

[16] Schacham, S. (1983) A Shortened Version of the Profile of Mood State. Journal of Personality Assessment, 47, 305-306. https://doi.org/10.1207/s15327752jpa4703 14

[17] Petrowski, K., Albani, C., Zenger, M., Brähler, E. and Schmalbach, B. (2021) Revised Short Screening Version of the Profile of Mood States (POMS) from the German General Population. Frontiers in Psychology, 12, Article ID: 631668. https://doi.org/10.3389/fpsyg.2021.631668

[18] Lorr, M., Daston, P. and Smith, I.R. (1967) An Analysis of Mood States. Educational Psychology, 27, 89-96. https://doi.org/10.1177/001316446702700109 
[19] McNair, D.M. and Lorr, M. (1964) Analysis of Moof in Neurotics. Journal of Abnormal and Social Psychology, 69, 620-627. https://doi.org/10.1037/h0040902

[20] Pagani, M.F., Lombardi, S., Guzzetti, O., Rimoldi, R., Furlan, P., Pizzinelli, G., Sandrone, G., Malfatto, S., Dell'Orto and Piccaluga, E. (1986) Power Spectral Analysis of Heart Rate and Arterial Pressure Variabilities as a Marker of Sympathovagal Interaction in Man and Conscious Dog. Circulation Research, 59, 178-193. https://doi.org/10.1161/01.RES.59.2.178

[21] Akselrod, S.D., Gordon, F.A., Ubel, D.C., et al. (1981) Power Spectrum Analysis of Rehabilitation Heart Rate Fluctuation; a Quantitative Probe of Heart-to-Beat Cardiovascular Control. Science, 213, 220-222. https://doi.org/10.1126/science.6166045

[22] Rivera-Lara, L., Zorrilla-Vaca, A., Healy, J., Ziai, W., Hogue, C., Geocadin, M., Radzik, B., Palmisano, C. and Mirski, A. (2019) Determining the Upper and Lower Limits of Cerebral Autoregulation with Cerebral Oximetry Autoregulation Curves: A Case Series. Critical Care Medicine, 46, e473-e477. https://doi.org/10.1097/CCM.0000000000003012

[23] Closhen, D., Berres, M., Werner, C., Engelhard, C. and Schramm, C. (2013) Influence of Beach Chair Position on Cerebral Oxygen Saturation: A Comparison of INVOS and FORE-SIGHT Cerebral Oximeter. Journal of Neurosurgical Anesthesiology, 25, 414-419. https://doi.org/10.1097/ANA.0b013e3182973349

[24] Manca, R., Marco, M. and Venneri, A. (2020) The Impact of COVID-19 Infection and Enforced Prolonged Social Isolation on Neuropsychiatric Symptoms in Older Adults with and without Dementia: A Review. Frontiers in Psychiatry, 11, Article ID: 585540. https://doi.org/10.3389/fpsyt.2020.585540

[25] Wang, Q., Davis, B., Gurney, E. and Xu, R. (2021) COVID-19 and Dementia: Analyses of Risk, Disparity, and Outcomes from Electronic Health Records in the US. Alzheimer's \& Dementia, 17, 1297-1306. https://doi.org/10.1002/alz.12296

[26] Sharma, S.K. (2021) COVID-19 and Dementia. Annals of Neurosciences, 28, 1-4. https://doi.org/10.1177/09727531211009420

[27] Numbers, K. and Brodaty, H. (2021) The Effects of the COVID-19 Pandemic on People with Dementia. Nature Reviews Neurology, 17, 69-70.

https://doi.org/10.1038/s41582-020-00450-Z

[28] Rainero, I., Bruni, A., Marra, C., Cagnin, A., Bonanni, L., Cupidi, C., Laganà, V., Rubino, E., Vacca1, A., Lorenzo, R., Provero, P., Isella, V., Vanacore, N., Agosta, F., Appollonio, I., Caffarra, P., Bussè, C., Sambati, R., Quaranta, D., Guglielmi, V., Logroscino, G., Filippi, M., Tedeschi, G., Ferrarese, C. and the SINdem COVID-19 Study Group (2021) The Impact of COVID-19 Quarantine on Patients with Dementia and Family Caregivers: A Nation-Wide Survey. Frontiers in Aging Neuroscience, 12, Article ID: 625781.

[29] Aruga, T. (2021) Healthcare Disaster Resilience for Superannuated Societies in Japan. JJOMT, 69, 144-150.

[30] Ishii, T., Yoshimi, K., Yeshioka, T., Takeda, M. and Yasutomi, M. (2021) A Case Report of a Super-Elderly Patient Infected with COVID-19. JJOMT, 69, 81-85.

[31] Matsumoto, T. (2021) COVID-19, Social Isolation and Clinical Practice in the Field of Addiction. Japanese Bulletin of Social Psychiatry, 30, 167-173.

[32] lshii, T., Yoshimi, K., Yeshioka, T., Takeda, M. and Yasutomi, M. (2021) A Case Report of a Super-Elderly Patient Infected with COVID-19. JJOMT, 69, 81-85. 